BRIEF

\title{
Use of Sunscreen and Indoor Tanning Devices Among a Nationally Representative Sample of High School Students, 2001-2011
}

\author{
Corey H. Basch, EdD, MPH; Charles E. Basch, PhD; Sonali Rajan, EdD, MS; \\ Kelly V. Ruggles, PhD
}

Suggested citation for this article: Basch CH, Basch CE, Rajan S, Ruggles KV. Use of Sunscreen and Indoor Tanning Devices Among a Nationally Representative Sample of High School Students, 2001-2011. Prev Chronic Dis 2014;11:140191. DOI: http://dx.doi.org/10.5888/pcd11.140191.

\section{PEER REVIEWED}

\section{Abstract}

Adolescents are particularly vulnerable to engaging in poor skinprotection behaviors. The objective of this study was to examine use of sunscreen and indoor tanning devices among a nationally representative sample of high school students during a 10-year period (2001-2011) using data from the Youth Risk Behavior Surveillance System. The percentage of youth who reported using sunscreen declined from $67.7 \%$ in 2001 to $56.1 \%$ in 2011 . The prevalence of using indoor tanning devices was highest among white females: $37.4 \%$ in 2009 and $29.3 \%$ in 2011 . These findings indicate the need for prevention efforts aimed at adolescents to reduce risks for skin cancer.

\section{Objective}

Skin cancer is the most common cancer in the United States (1). From 2001 to 2010, incidence of melanoma increased annually by $1.6 \%$ among men and by $1.4 \%$ among women (2). Preventive measures, such as using sunscreen and not using artificial tanning devices, are recommended to avoid developing skin cancer $(2,3)$. Skin-protection behaviors are especially important for children and adolescents because sun exposure during childhood and adolescence directly influences the development of skin cancer later in life (3). The objective of this study was to examine skin-protection behaviors among a nationally representative sample of high school students during a 10-year period (2001-2011) using data from the Centers for Disease Control and Prevention's (CDC's) Youth Risk Behavior Surveillance System (YRBSS).

\section{Methods}

The CDC collects data through the YRBSS from a nationally representative sample of public, private, and parochial high schools every 2 years (4). The data represent each sex, race/ethnicity group, high school grade, and nearly every US state. Our study focused on the analysis of responses to 2 YRBSS questions: 1) When you are outside for more than one hour on a sunny day, how often do you wear sunscreen with an SPF of 15 or higher? and 2) During the past 12 months, how many times did you use an indoor tanning device, such as a sunlamp, sunbed, or tanning booth? The response format for each item has multiple categories and was subsequently dichotomized according to CDC methods (4). For the item on sunscreen use, the possible responses are "never," "rarely," "sometimes," "most of the time," and "always." We dichotomized this variable into those who reported ever using sunscreen in the previous 12 months and those who reported never using sunscreen. For the item on indoor tanning devices, we dichotomized responses $(0,1$ or $2,3-9,10-19,20-39$, and $\geq 40$ times $)$ into those who reported no use and those who reported any use; we further dichotomized the data into 1) used 1 to 19 times and 2) used more than 20 times (ie, heavy use). The item on sunscreen use was asked in the same way in all 6 years of survey administration studied (2001, 2003, 2005, 2007, 2009, and 2011). The item on use of tanning devices was asked only in 2009 and 2011.

We calculated for each survey year the percentage of youth who reported wearing sunscreen and the percentage of youth who reported using a tanning device. We calculated percentages by sex (male or female), race/ethnicity (Hispanic, black, white, and "other"), and grade level (9-12), and various combinations of sub- 
groups. We excluded from analysis surveys that were missing data ( $<5 \%$ of surveys). All YRBSS data were weighted to match national population proportions (4). We created a heat map for data on sunscreen use, which allows readers to visualize fluctuations in prevalence. This study was deemed to be exempt by the institutional review board at William Paterson University and was approved by the institutional review board at Teachers College, Columbia University, and New York University Langone Medical Center.

\section{Results}

The overall percentage of respondents who reported using sunscreen decreased from $67.7 \%$ in 2001 to $56.1 \%$ in 2011 (Figure). The lowest prevalence during the study period was in 2005 (55.3\%). We observed similar patterns among white males and females. Overall, a greater percentage of females than males consistently reported using sunscreen. Similarly, white respondents consistently reported using sunscreen at higher rates than their black, Hispanic, and other racial/ethnic counterparts. Rates of sunscreen use were similar across grade levels.

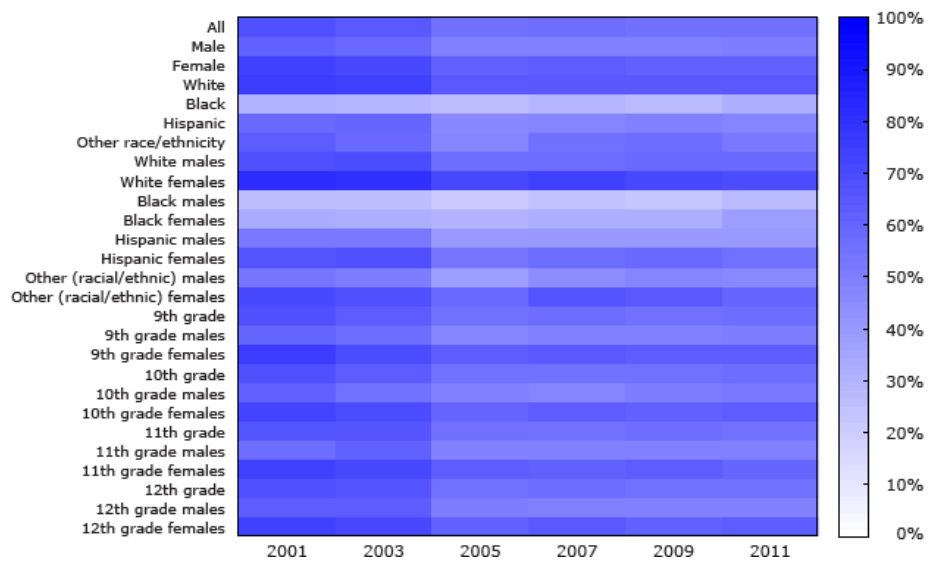

Figure. Prevalence (\%) of sunscreen use among a nationally representative sample of high school students, 2001-2011. Data source: Youth Risk Behavior Surveillance System.

The percentage of respondents who reported using indoor tanning devices was $15.6 \%$ in 2009 and $13.3 \%$ in 2011 (Table). In 2009 and 2011 , a greater percentage of female respondents $(25.4 \%$ in $2009 ; 20.9 \%$ in 2011$)$ than male respondents $(6.7 \%$ in $2009 ; 6.2 \%$ in 2011) reported using indoor tanning devices. The use of indoor tanning devices was greatest among white females compared with all other subgroups: $37.4 \%$ in 2009 and $29.3 \%$ in 2011 . The percentage of respondents who reported heavy use of indoor tanning devices in the previous 12 months was highest among white fe- males $(12.4 \%$ in 2009 and $11.0 \%$ in 2011$)$. We also found that the prevalence of using a tanning device increased as grade level increased.

\section{Discussion}

This is the first study to examine the most recent YRBSS data on skin-protection behavior across 10 years and multiple demographic subgroups. Other studies have examined YRBSS data on this topic, and their findings are similar to ours. A study in 2009 examined the number of high school students who used tanning devices during a 12-month period and found that although only $15.6 \%$ of students used a tanning device, nearly half of them did so 10 or more times (5). A study examining trends in sunscreen use during 1999-2009 found an increase in the percentage of high school students who never or rarely wore sunscreen on a sunny day for more than an hour (6).

A limitation to our study is that YRBSS data are cross-sectional; that data represent only certain points in time should be considered in the interpretation of prevalence patterns. Data are also based on self-report. Despite these limitations, the sample sizes are large, and the study fills a gap in knowledge.

Overexposure to ultraviolet radiation is a risk factor for skin cancer (7). Prevention of overexposure is especially important during childhood and adolescence. Our research supports past findings that adolescents practice behaviors that increase the risk for skin cancer $(8,9)$. Our findings also illustrate that certain demographic subgroups - girls and young women - are especially at risk for engaging in unsafe skin-protection practices; future preventive efforts should prioritize these young people.

\section{Acknowledgments}

No financial support was received for this project.

\section{Author Information}

Corresponding Author: Corey H. Basch, EdD, MPH, Assistant Professor, Department of Public Health, William Paterson University, Wing 150, Wayne, NJ 07470. Telephone: 973-7202603. E-mail: baschc@wpunj.edu.

Author Affiliations: Charles E. Basch, Sonali Rajan, Teachers College, Columbia University, New York, New York; Kelly V. Ruggles, Center for Health Informatics and Bioinformatics, New York University Langone Medical Center, New York, New York.

The opinions expressed by authors contributing to this journal do not necessarily reflect the opinions of the U.S. Department of Health and Human Services, the Public Health Service, the Centers for Disease Control and Prevention, or the authors' affiliated institutions. 


\section{References}

1. Skin Cancer Statistics. Atlanta (GA): Centers for Disease Control and Prevention; 2013. http://www.cdc.gov/cancer/skin/ statistics/. Accessed April 4, 2014.

2. Basic information about skin cancer. Atlanta (GA): Centers for Disease Control and Prevention; 2014. http://www.cdc.gov/ cancer/skin/basic_info/index.htm. Accessed April 4, 2014.

3. How can I protect my children from the sun? Atlanta (GA): Centers for Disease Control and Prevention; 2013. http:// www.cdc.gov/cancer/skin/basic_info/children.htm. Accessed April 4, 2014.

4. Centers for Disease Control and Prevention (CDC), Brener ND, Kann L, Shanklin S, Kinchen S, Eaton DK, et al. Methodology of the Youth Risk Behavior Surveillance System - 2013. MMWR Surveill Summ 2013;62(RR-1):1-20.

5. Guy GP, Tai E, Richardson LC. Use of indoor tanning devices by high school students in the United States, 2009. Prev Chronic Dis 2011;8(5):A116.

6. Jones SE, Saraiya M, Miyamoto J, Berkowitz Z. Trends in sunscreen use among U.S. high school students: 1999-2009. J Adolesc Health 2012;50(3):304-7.

7. Balk SJ. Ultraviolet radiation: a hazard to children and adolescents. Pediatrics 2011;127(3):e791-817.

8. Geller AC, Colditz G, Oliveria S, Emmons K, Jorgensen C, Aweh GN, et al. Use of sunscreen, sunburning rates, and tanning bed use among more than 10,000 US children and adolescents. Pediatrics 2002;109(6):1009-14.

9. Demko CA, Borawski EA, Debanne SM, Cooper KD, Stange KC. Use of indoor tanning facilities by white adolescents in the United States. Arch Pediatr Adolesc Med 2003;157(9):854-60.

The opinions expressed by authors contributing to this journal do not necessarily reflect the opinions of the U.S. Department of Health and Human Services, the Public Health Service, the Centers for Disease Control and Prevention, or the authors' affiliated institutions. 


\section{Table}

Table. Prevalence (\%) of Using Indoor Tanning Devices Among a Nationally Representative Sample of High School Students, 2009 and 2011

\begin{tabular}{|c|c|c|}
\hline Demographic group & 2009 & 2011 \\
\hline All & 15.6 & 13.3 \\
\hline \multicolumn{3}{|l|}{ Sex } \\
\hline Male & 6.7 & 6.2 \\
\hline Female & 25.4 & 20.9 \\
\hline \multicolumn{3}{|l|}{ Race/ethnicity } \\
\hline White & 21.1 & 17.4 \\
\hline Black & 4.5 & 3.9 \\
\hline Hispanic & 8.2 & 7.6 \\
\hline Other & 7.9 & 9.0 \\
\hline \multicolumn{3}{|l|}{ Race/ethnicity and sex } \\
\hline White male & 7.0 & 6.2 \\
\hline White female & 37.4 & 29.3 \\
\hline Black male & 6.1 & 4.5 \\
\hline Black female & 2.7 & 3.3 \\
\hline Hispanic male & 5.8 & 5.7 \\
\hline Hispanic female & 10.6 & 9.6 \\
\hline Other (racial/ethnic) male & 5.3 & 8.2 \\
\hline Other (racial/ethnic) female & 10.3 & 9.8 \\
\hline \multicolumn{3}{|l|}{ Grade level and sex } \\
\hline 9th grade (all) & 10.5 & 8.1 \\
\hline 9th-grade male & 5.9 & 4.5 \\
\hline 9th-grade female & 16.0 & 11.7 \\
\hline 10th grade (all) & 13.4 & 10.1 \\
\hline 10th-grade male & 4.6 & 4.9 \\
\hline 10th-grade female & 23.2 & 15.7 \\
\hline 11th grade (all) & 18.2 & 16.4 \\
\hline 11th-grade male & 7.0 & 6.8 \\
\hline 11th-grade female & 30.3 & 26.5 \\
\hline 12th grade (all) & 21.7 & 19.7 \\
\hline 12th-grade male & 10.0 & 8.5 \\
\hline 12th-grade female & 33.8 & 31.8 \\
\hline
\end{tabular}

\footnotetext{
The opinions expressed by authors contributing to this journal do not necessarily reflect the opinions of the U.S. Department of Health and Human Services, the Public Health Service, the Centers for Disease Control and Prevention, or the authors' affiliated institutions.
}

4 Centers for Disease Control and Prevention • www.cdc.gov/pcd/issues/2014/14_0191.htm 